\title{
Do gesto ao símbolo: a teoria de Henri Wallon sobre a formação simbólica
}

\section{From gesture to symbol: the theory of Henri Wallon about symbolic formation}

\author{
Dener Luiz da Silva*
}

\begin{abstract}
RESUMO
Henri Wallon, filósofo, médico e psicólogo francês, contribuiu para a psicologia não apenas com uma teoria da emoção ou ainda com suas discussões e divergências com Jean Piaget. Dentre suas contribuições pouco discutidas estão sua teoria sobre a inteligência, suas discussões sobre a origem e o desenvolvimento do pensamento discursivo nas crianças e, talvez menos conhecidas, suas reflexões e proposições sobre a transição entre uma inteligência sensório-motora (caracterizada pela capacidade de resolver problemas práticos, mas sem o auxílio da reflexão) e uma outra, inteligência discursiva (caracterizada pela utilização e intermediação dos símbolos e representações). Sabe-se que sua proposição para essa transição, diversamente de Piaget, que ressalta a continuidade e a preparação do simbólico pelo esquematismo sensório-motor, é marcada justamente pela não continuidade entre uma inteligência e outra, pela intromissão de fatores externos tais como a cultura, o social e a linguagem, e pela complexa interação entre todos esses fatores. Para melhor compreender a proposta walloniana sobre a formação do símbolo é necessário, pois, que ingressemos na sua teoria como um todo, buscando decifrar seus conceitos de emoção, comportamento simbólico, inteligência, fatores de desenvolvimento e outros. Em uma sociedade como a nossa, baseada no comportamento simbólico, entender como se dá, qual a origem e o desenvolvimento do pensamento simbólico podem ser conhecimentos de grande valia.

Palavras-chave: Wallon; formação simbólica.
\end{abstract}

* Professor adjunto da Universidade Federal de São João Del Rei / MG. Doutor em Educação pela UFMG. E-mail: densilva@ufsj.edu.br 


\begin{abstract}
Henri Wallon, French philosopher, physician, and psychologist, has given psychology contribution not only with his emotion theory and with his arguments and disagreements with Jean Piaget. Among his less discussed contributions are the theory about intelligence, the discussions about the origin and development in children's discoursing thought, and, maybe less known, the reflections and propositions about the transition between sensory-motor intelligence (characterized by the capacity to solve practical problems, but without the aid of reflection) and discoursing intelligence (characterized by the use and intermediation of symbols and representations). It is known that his proposition for this transition, diversely from Piaget, who emphasizes continuity and preparation of the symbolic attributes by sensory-motor schematism, is in fact marked by the non-continuity between one intelligence and the other, by the interference of external elements such as culture, social aspects, and language, and by the complex interaction between all these elements. In order to better understand the Wallonian proposal about symbol formation it is necessary, therefore, to study his theory as a whole, trying to decode his concepts on emotion, symbolic behavior, intelligence, development factor, and so forth. In a society like ours, based on symbolic behavior, understanding the way it occurs, its origin, and the development of symbolic thought can be worthwhile.

Key-words: Wallon; symbolic formation.
\end{abstract}

O pensamento simbólico ou representacional é o que melhor qualifica a psicologia humana (Deloache, 1996, 2005). Vivemos em uma sociedade baseada em trocas simbólicas (CASSIRER, 1945). Assim, explicar o pensamento simbólico continua sendo um dos grandes problemas para a psicologia. Há potenciais usos de um conhecimento sobre o tema na área educacional: aprendizagem, inteligência, imitação, jogo, linguagem, valores, parecem ser todos, no homem, atividades mediadas, em maior ou menor medida, por símbolos. No presente texto buscaremos apresentar a teoria de Henri Wallon sobre o nascimento do pensamento simbólico. Primeiramente, apresentamos ao leitor uma breve biografia do psicólogo francês, procurando buscar elementos que possam nos auxiliar na reconstrução dos contextos teórico e histórico que possam ter influído na produção da teoria walloniana. Num segundo momento, passamos para a descrição dos principais conceitos e a compreensão da teoria como um todo. No terceiro e quarto momentos, apresentamos o contexto e delimitamos o tema que buscamos elucidar: como é compreendida por Wallon a transição entre o comportamento do bebê, no qual imperam elementos concretos, e 
aquele da criança pequena, identificado pelo uso de símbolos e signos? Por fim, apresentamos de forma rápida alguns possíveis intercâmbios teóricos que possam ser realizados entre a obra de Wallon e a de outros autores da psicologia contemporânea; nosso interesse é o de evidenciar o valor heurístico ainda presente na obra de Wallon no que concerne ao entendimento de muitas das temáticas da psicologia científica.

\section{Biografia de Wallon}

Wallon nasceu em 15 de junho de 1879 em Paris e aí viveu toda sua vida. Terceiro filho de uma família aristocrática, seu avô, de quem herdou o nome, fora historiador e político importante para a história da França, pois por sua intervenção o termo república começou a fazer parte da constituição daquele país. ${ }^{1}$

Uma família na qual se respirava a política, a justiça e a democracia. Um dos eventos mais marcantes da infância de Wallon, segundo ele próprio, foi a morte do escritor e poeta Victor Hugo. O pai de Wallon, o arquiteto Paul Alexandre Joseph Wallon, durante o jantar, lê trechos do poeta para os filhos e, em seguida, dirige-se com estes para visitar a casa do escritor, onde ocorria o velório. Zazzo (1993), ao recordar suas conversas com Wallon sobre o assunto, transcreve a passagem do seguinte modo: "Quem foi este homem, papai? - Um poeta, um escritor, responde seu pai, mas também um homem que lutou pela liberdade, pelo bem contra o mal, pela defesa dos pobres. É preciso fazer como ele quando você crescer" (ZAZZO, 1993, p. 9).

Não se conhece muito mais sobre a infância e a adolescência de Wallon ou sobre sua vida familiar (a família Wallon era composta de 7 irmãos).

Quanto a seus estudos superiores, decide, primeiramente, fazer a Escola Normal Superior e tentar a carreira de professor de Filosofia (Agregation). Ali recebe uma educação filosófica sólida, nos parâmetros da filosofia "de Kant a Hegel" (JALLEY, 2002). Enquanto estudante do Normal Superior, foi influenciado pelo professor Frédéric Rauh, filósofo que escrevera livros sobre a psicologia e sobre a investigação das experiências morais. ${ }^{2}$ Ao receber sua agregation ${ }^{3} \mathrm{em} 1902$, Wallon irá lecionar, por um ano, no Liceu Bar-le-Duc, na periferia de Paris.

${ }^{1}$ Trata-se da Terceira República (1875 a 1940), que se instalou depois da queda do Segundo Império, em 1870.

2 Frédéric Rauh (1861-1909) publicou "Essai sur le fondement métaphysique de la morale" (1890) e "L'Expérience morale" (1903).

${ }^{3}$ Concurso público que garantia àqueles que passassem a contratação por parte do governo. 
Ele se mostra descontente com a atividade repetitiva de professor no secundário e procura, então, a carreira de medicina, à época o caminho indicado por Théodule Ribot (1839-1916), o pai da psicologia francesa, para que se pudesse ingressar firmemente em uma psicologia científica. Formado em 1908, ele imediatamente torna-se assistente do professor Nageotte (18661948), eminente histopatologista, e com ele inicia suas atividades no Hospital de Bicêtre e, algum tempo depois, Salpêtrière, onde irá coletar os dados para a confecção de sua tese de doutorado - e também seu primeiro livro -, defendida apenas em 1925, sob o título de L'enfant turbulent (A criança agitada).

O motivo do atraso para a defesa se deve à colaboração de Wallon na Primeira Grande Guerra (1914-1918) e ao seu engajamento como mestre de conferências de Psicologia Infantil na Sorbonne, entre 1920 a 1937. O episódio da guerra, em especial, irá causar um grande impacto nas idéias que Wallon alimentava sobre o desenvolvimento infantil e sobre as relações entre a emoção e a razão. Como médico do exército francês, teve a oportunidade de cuidar de inúmeros feridos neurológicos, e especialmente dos soldados afetados por traumas de guerra. Wallon observou a curiosa relação que havia entre um maior número e maior intensidade dos traumas de guerra nos soldados do que em seus superiores. Haveria alguma relação entre a racionalização e controle emocional que os responsáveis pelas tropas tinham de utilizar-se e a sua saúde mental futura?

A resposta a essa pergunta irá determinar grande parte da produção de Wallon, que procurará mostrar a função da emoção na psicologia humana: ela é composta de reações orgânicas, controladas por centros cerebrais específicos, e caracterizada por transformações corporais visíveis. Tais transformações são os resultados da interação entre as funções tônica e clônica. Sua principal função é mobilizar o meio social. Possibilita o nascimento da consciência e, uma vez que esta nasce, opõe-se a ela. Eis o início da psicologia dialética de Wallon.

Mas, voltando à década de 1920, veremos Wallon continuando seu trabalho de atendimento médico pedo-psiquiátrico, agora não mais nos hospitais psiquiátricos, mas, exclusivamente, no Laboratório de Psicobiologia em anexo a uma escola na periferia de Paris. Aproximar-se das crianças, de seu hábitat, eis o desejo deste que foi, segundo Zazzo (1993), dos psicólogos médicos (a lista é grande, mas poderíamos citar Janet, Dumas, Claparède, Freud, Jung, Reich, Lacan, Frankl, etc.), o mais médico de todos, querendo dizer, com isso, não que este tenha subordinado a psicologia à medicina, mas referindo-se ao fato de que, durante toda sua vida, mesmo quando já não podia locomover-se sozinho, continuar sua rotina de consultações. 
Na mesma década, irá engajar-se como presidente da Sociedade Francesa de Psicologia (1927) e como diretor de estudos na École Pratique de Hautes Études, cargo que lhe permitia prosseguir com as pesquisas no laboratório por ele fundado. Em 1929, juntamente com o amigo Henri Pièron - que mais tarde se tornará a grande referência da psicologia experimental na França -, irá fundar o Instituto Nacional do Estudo do Trabalho e de Orientação Profissional. É dessa incursão na área da Psicologia do Trabalho e da orientação profissional que surgirá seu terceiro livro, "Princípios de psicologia aplicada", publicado em 1930. ${ }^{4}$

Mas, se até então Wallon se configurava como um dos importantes nomes da psicologia infantil na França, contribuindo com teses originais sobre os elementos presentes no desenvolvimento infantil - o papel importante dado à emoção, à descrição de algumas síndromes psicomotoras apresentadas em seu primeiro livro, o esforço em efetuar uma psicologia científica, sem recursos à metafísica ou ao espiritualismo -, a teoria walloniana encontrava-se, ainda, em seus primórdios e não era difícil classificá-la, à época, como uma abordagem que reduz todas as manifestações psicológicas ao seu componente orgânico, uma teoria organicista. René Zazzo (1910-1995), que o sucederá na direção do Laboratório de Psicobiologia da Criança, conta que seu primeiro contato com Wallon, na Sorbonne, ocorrera a partir do rótulo organicista, que ele considerou, mais tarde, equivocado, uma vez que

Não há dúvida de que "no decurso do seu desenvolvimento, a função só pode consolidar-se num conjunto evolutivo cujas condições são orgânicas", não há dúvida de que "a evolução psíquica não pode antecipar-se às estruturas orgânicas". E é desta dependência que deriva a impossibilidade de desenvolver na criança mediante simples exercício aptidões ainda não amadurecidas. Mas esta dependência e este condicionamento não impedem as funções psíquicas, uma vez existentes, de pertencer a um mundo de causas e de efeitos que já não são de natureza orgânica. Entre os dois sistemas de condições orgânicas e de condições sociais existe uma margem para a atividade de todos e de cada um em que "as combinações de objetivos e de aptidões, de reações recíprocas, de incidência em cascata são suscetíveis de todos os graus entre o conformismo e o poliformismo, entre a coação e a liberdade". Esta margem define o domínio próprio da psicologia, um plano da realidade em que o psíquico não se define nem como substância

4 O segundo livro de Wallon versa sobre "Psicologie Pathologique". Nele, Wallon procura aprofundar as teses da psicologia que estudam os distúrbios psiquiátricos. Este é o único livro de Wallon que não foi reeditado, sendo também pouco citado por ele próprio no decorrer das outras obras. 
material nem como substância espiritual, mas como uma conduta original num mundo em que constitui, verdadeiramente, uma novidade (ZAZZO, 1978, p. 87-88).

Wallon, portanto, desde seus primeiros textos, busca produzir uma nova psicologia, uma solução para os reducionismos tanto do materialismo mecanicista-organicista quanto do espiritualismo. Por esse motivo, o que é e como se constitui a consciência torna-se o tema central de suas primeiras investigações, ainda na segunda década do século XX. ${ }^{5}$

No entanto, a explicitação teórica de uma concepção que ultrapassasse a dicotomia orgânico-social muito mais conforme ao materialismo dialético (Marx e Engels) irá ocorrer somente na década de 1930. A partir de uma viagem à Rússia, para um congresso de Psicologia Clínica (1931), Wallon é convidado a participar do Círculo da Nova Rússia, um grupo de intelectuais que queria aproximar-se das teses marxistas em seus respectivos campos de interesse. É a partir desse envolvimento com o Círculo da Nova Rússia que veremos Wallon definindo sua psicologia como propriamente dialética. Em 1934, Wallon irá publicar aquele que é considerado seu primeiro grande livro, "As origens do caráter", no qual já se encontram desenvolvidas as suas principais teses sobre o desenvolvimento do eu e o papel da emoção e do movimento nesse desenvolvimento. Segundo Zazzo (1989), as idéias ali apresentadas irão:

Inspirar alguns anos mais tarde René Spitz ${ }^{6}$ quando este procurará interpretar os efeitos da perda da mãe pelo recém-nascido. Apesar disso, esse livro não tem a elegância de apresentação ou a lógica de demonstração que possam seduzir um leitor apressado: é uma compilação de artigos e conferências feitas na Sorbonne no decorrer dos anos precedentes (ZAZZO, 1989, p. 180).

${ }^{5}$ Cf., por exemplo, os artigos "La conscience et la vie subconsciente" (1920); "La conscience et la conscience du moi" (1921); "Le problème biologique de la conscience" (1921). Aqui é evidente o esforço de Wallon por superar o organicismo e espiritualismo explicativo de sua época, mas, não obstante, talvez pelo próprio linguajar ainda bastante impregnado pelo vocabulário médico, a tese organicista parece ser a que se sobressai.

${ }^{6}$ René Spitz (1887-1974) foi um psicanalista húngaro que construiu sua carreira nos Estados Unidos. Seu maior interesse era investigar a relação entre o bebê e sua mãe. Cunhou os termos "hospitalismo" e "depressão anaclítica" para melhor explicar as reações emocionais e psicológicas dos bebês deixados em isolamento em situação de internação hospitalar. 
É ali, igualmente, que Wallon irá descrever o que vem a ser o estágio do espelho, momento do desenvolvimento infantil, por volta dos três anos, em que a criança constrói uma imagem externa, um esquema corporal de si. $\mathrm{O} e u$ não é um dado original ou inicial na psicologia humana, senão o fruto de uma longa trajetória, repleta de momentos críticos ou crises. Mas, para Wallon, tais crises não são vistas como necessariamente negativas, ao contrário, são momentos indispensáveis para a constituição da personalidade. A crise da adolescência, por exemplo, pode ser um importante momento em que o jovem toma para si modelos por ele mesmo escolhidos e busca livrar-se daqueles impostos até então. Certamente, como decorrência desse momento crítico podem surgir conflitos explícitos, mas Wallon alerta para o fato de que as crises no desenvolvimento não são sinônimo de conflito. Outra importante definição que se dá nesse momento é a do conceito de caráter. Para Wallon, o caráter é o componente mais original de cada ser humano, "esta espécie de índice individual" (WALlon, 1934/1986, p. 26). Trata-se do conjunto de respostas orgânicas e psicológicas mais ou menos estáveis que o sujeito empreende diante das solicitações do meio externo. Ele tem uma origem orgânica, portanto, mas não se resume a ela, já que na concepção dialética walloniana filiação não significa causalidade. No entanto, é a partir do caráter, este núcleo duro, que se acrescentarão as influências sociais, culturais e históricas que irão culminar na personalidade, que, por esse motivo, sofre variações e tem um desenvolvimento próprio ao longo da ontogenia.

No ano seguinte à publicação de As origens do caráter, Wallon será eleito, finalmente, para o quadro de professores do Collège de France. A tradicional casa universitária da França demorará ainda dois anos para admiti-lo concretamente. As dificuldades para a aceitação de Wallon no quadro universitário francês decorrem da política interna da instituição e, segundo muitos autores (JALLEY, 2006; Nicolas, 2003; ZAZZO, 1978), pelo cada vez mais explícito engajamento político de Wallon às teses marxistas. Embora ele tenha se filiado ao partido socialista em 1931 e dele se retirado por não concordar com as suas opções eleitoreiras, por ocasião da invasão alemã à França, e como resposta à morte de dois jovens intelectuais próximos a Wallon, irá se filiar (1942) agora ao partido comunista, permanecendo neste até o final de sua vida. O engajamento político de Wallon, no entanto, não é, em última instância, partidário. No final da década de 1930, irá viajar até a capital espanhola para, juntamente com estudantes e intelectuais, protestar contra a nascente ditadura franquista. ${ }^{7}$ Durante a ocupação alemã,

${ }^{7} \mathrm{O}$ franquismo é o regime político baseado no fascismo (Mussolini) aplicado na Espanha de 1939 a 1975, período em que o país foi governado pelo ditador Francisco Franco. 
permanecerá em Paris com suas consultações pediátricas, mesmo correndo o risco de ser preso pelos agentes da Gestapo.

Em 1944, nos últimos momentos antes do término da guerra, é indicado como Ministro da Educação do governo da resistência, cargo que ocupa por apenas um mês. Entretanto, sua ligação com a educação é profunda, e não apenas teórica. Já na sua aula inaugural no Collège de France (1937), ele deixa claro que o vínculo ideal entre psicologia e pedagogia não é de submissão entre essas duas disciplinas, mas de integração e fortalecimento mútuo. A psicologia pode oferecer muito à pedagogia, seja propondo teorias mais condizentes com a tarefa de educar, seja esclarecendo os vários estágios e períodos do desenvolvimento pelos quais passa o aluno. Mas a pedagogia, igualmente, pode complementar o olhar psicológico, fornecendo-lhe não só o material para seu trabalho, mas indicando e problematizando situações não perceptíveis ao psicólogo.

O engajamento político e prático de Wallon com a educação pode ser visto ainda por seu projeto, em co-autoria com o físico Paul Langevin (18721946), de uma reforma educacional, que será publicado em 1947, mas que jamais será totalmente aplicado no sistema de ensino francês. Ali, dentre tantas modificações sugeridas pelos autores do projeto, vemos a compreensão do aprendizado como um trabalho a ser realizado pelo estudante. Daí, então, a necessidade do pagamento de bolsas que pudessem auxiliar e reforçar o trabalho do aluno.

Em 1938, aceitando o convite de seu amigo, o historiador Lucien Febvre, Wallon coordena e redige os trabalhos para a publicação do $8^{\circ}$ Tomo da Enciclopédia Francesa. O título que ele preferirá adotar para esse volume é, por si só, elucidativo: a vida mental. Tratava-se, pois, da busca por um texto que resumisse os principais achados da ciência psicológica até então sem, no entanto, cair no tradicional modelo dos manuais psicológicos. Era preciso, dizia Wallon, aproximar o saber psicológico da vida real, concreta, cotidiana do homem contemporâneo. É por esse motivo que os vários capítulos daquela enciclopédia, muitos deles redigidos pelo próprio Wallon, irão versar sobre temas como a pessoa no trabalho, na escola, na família, etc.

A década de 1940, apesar da grande conturbação provocada pela Segunda Grande Guerra (1939-1945), será aquela em que Wallon publicará seus mais importantes livros: A evolução psicológica da criança (1941); Do ato ao pensamento (1942) e As origens do pensamento na criança (1945). No primeiro desses livros, teremos a explicitação das fases do desenvolvimento propostas por Wallon, agora de uma forma mais acabada. São elas:

Estágio impulsivo-emocional ( 0 a 1 ano) 
Estágio sensório-motor e projetivo (1 a 3 anos)

Estágio do personalismo ( 3 a $6 / 7$ anos)

Estágio categorial (7 a 11 anos)

Estágio da adolescência (12 a 18 anos)

É igualmente neste livro que Wallon indicará que a transição entre esses diferentes estágios se dá por mecanismos de alternância e preponderância funcional, entre fases com ênfase nos aspectos emocionais e outras com ênfase cognitiva. Ou seja, inicialmente, no decorrer do desenvolvimento, a criança irá dispor apenas dos seus movimentos e de seu comportamento emocional para interagir com seu meio. À medida que ela constrói um repertório mais ou menos estável de reações motoras e emocionais, entendidas por Wallon $(1934,1941)$ como já um prenúncio de comunicação e de consciência, ela passa a voltar-se, no estágio sensório-motor e projetivo, com mais ênfase para o mundo externo. É a fase da inteligência das situações, ativada para responder a uma situação e não a um objeto isolado no real. É ainda uma inteligência sincrética que se caracteriza pelo responder às exigências do real não mais por meio de gestos sem sentido ou impulsivos, mas por uma coordenação cada vez mais apurada e coordenada entre meios e fins. A criança de um ano de idade que puxa um objeto para alcançar um outro, ou que decide modificar o gesto ou a própria posição do corpo para alcançar e pegar algo de seu interesse, até então inalcançável, faz uso da inteligência das situações. Ao final dessa fase da inteligência sensóriomotora, graças ao amadurecimento dos centros nervosos e ao nascimento da função simbólica, passa a se projetar, ou seja, a planificar e a representar suas ações num novo plano, não mais concreto, mas virtual.

Alcançada essa etapa, que exige superar a oposição entre o mundo real concreto e o mundo igualmente real, mas virtualizado, desdobramento do primeiro, a criança volta-se para a tarefa de construir-se a si. É então que surge a crise do personalismo, momento no qual, com seu eu ainda instável e sincreticamente amalgamado ao outro, passa a efetuar o trabalho de diferenciação entre este eu nascente e o outro. É preciso se opor ao outro para afirmar a si. $\mathrm{Na}$ psicanálise tem-se o momento do complexo de Édipo como equivalente mais próximo dessa fase. Vencida parcialmente essa diferenciação, estabilizadas as zonas psicológicas denominadas eu e outro, na etapa seguinte a criança volta-se, uma vez mais, para seu ambiente externo. É o período categorial, no qual, com o auxílio da linguagem, a criança irá categorizar e classificar todos os eventos e situações que lhe apareçam. Não se trata, porém, de uma fase racionalista, uma vez que o sincretismo marcado pela confusão entre o $e u$ e o outro, pela diferenciação entre o interno (meu) e o externo, é lenta e 
só culminará em sua plenitude após a crise da adolescência. Assim, de início a criança classifica e organiza seu mundo com base naquilo que este mundo significa e como a afeta.

Será em As origens do pensamento na criança (1945) que Wallon descreverá em pormenores esse longo processo que culminará no pensamento do adulto.

A fase da adolescência, como já afirmado, constitui-se num retorno ao trabalho iniciado no estágio do personalismo. Agora, a criança terá à sua disposição inúmeros instrumentos - modos de pensar, linguagem, instrumentos culturais, ritos, etc. - para lidar com as novas transformações orgânicas e sociais que a vida lhe proporciona e para a definição, já dentro de patamares mais conscientes e voluntários, sobre o problema da identidade. A superação da crise da adolescência será tão melhor, e mais adequadamente resolvida, quanto melhores as condições orgânicas, pessoais, familiares, sociais, culturais e históricas para essa resolução.

É no segundo livro desse período, Do ato ao pensamento (1942), que Wallon irá apresentar suas teses sobre a passagem entre a inteligência das situações, própria do bebê de 0 a 3 anos, e aquela que se caracteriza pelo uso dos símbolos e signos, que surge na criança a partir do segundo ano de vida. É a explicação da representação.

Não obstante sua intensa produção teórica, de continuar à frente do Laboratório de Psicobiologia da criança e suas inúmeras pesquisas, Wallon ainda militou noutras frentes. Foi o responsável pela emenda que introduziu o serviço de psicologia escolar nas escolas públicas francesas (1944); atuou como deputado na Assembléia Constituinte que se configurou logo após a Segunda Grande Guerra (1946); editou a revista Enfance (1948); presidiu a Sociedade Médico-Psicológica (1951). Em 1954, torna-se presidente da Sociedade Francesa de Educação Nova e está a frente, no mesmo ano, das Jornadas Internacionais de Psicologia da Criança.

Embora, provavelmente como decorrência de seu engajamento político e de suas escolhas ideológicas, Wallon tenha tido dificuldades em criticar o regime stalinista da então União Soviética, em sua defesa podemos constatar que, por ocasião da Revolta de Budapeste (1956), que culminou no massacre, por parte das tropas soviéticas, de quase 25.000 jovens húngaros, assinou um manifesto junto a 9 outros grandes intelectuais ou personagens públicos contra a intervenção militar e o apoio do partido comunista ao exército soviético.

Sem filhos, pouco se sabe sobre seu relacionamento com Germaine Anne Roussey Wallon, apenas que poucos meses após a morte de sua esposa (1953), Wallon sofre um acidente de carro (é atropelado) e acaba sendo obrigado a ficar 
os anos finais de sua vida de cama. Não obstante, desde então contar-se-ão cerca de 80 novas publicações até a data de sua morte, em $1^{\circ}$ de dezembro de 1962.

\section{A teoria walloniana: conceitos básicos}

A teoria de Wallon é identificada como Psicologia da Pessoa Completa (GALVÃo, 1996), pois visa justamente à produção de um saber psicológico que leve em conta a totalidade da pessoa (consciência, eu, emoções, representações, etc.), em suas condições concretas de existência.

Seu método de investigação, denominado método concreto-multidimensional (TrAn-Thong, 1987), fortemente baseado no materialismo dialético (Marx e Engels), caracteriza-se pela comparação de diferentes planos de atividade (comparar o homem contemporâneo com o homem dito "primitivo", comparar o animal com o homem, comparar a criança com o animal e com o homem primitivo, o doente com o saudável, etc.), bem como a busca pelas diferenças, mais do que as semelhanças, pois as primeiras fazem tão parte do real quanto as segundas. Segundo Wallon, o investigador deveria buscar superar o limite da racionalidade linear e redutora, que tudo condiciona a um plano causal único. Não é coincidência, deste modo, que alguns dos títulos de suas investigações versarão sobre "AS" origens, e não "A" origem, de um determinado fenômeno ou comportamento psicológico.

Sua visão dialética dos fenômenos psicológicos e sua escrita, que reflete em grande parte esse seu raciocínio, são algumas das dificuldades que o leitor iniciante tem de suplantar para compreender as idéias wallonianas.

A emoção é a resposta orgânica, sustentada por centros nervosos específicos, de que o bebê dispõe para lidar com seu meio. Mas ela não é apenas instrumental, é igualmente expressiva ou comunicativa. Sua principal função na espécie humana é a ativação do outro. Por se manifestar por meio de movimentos e de conformações físicas expressivas que, por assim dizer, moldam o corpo (função proprioplástica), a emoção traz, em si, a possibilidade de ser interpretada e de provocar no outro respostas correspondentes e complementares. Trata-se de uma protolinguagem, ou linguagem anterior à linguagem, esta última entendida como comunicação por material simbólico, signos e símbolos. 
A emoção, tornada consciente, atravessada pelo conteúdo e pelas significações dadas pela cultura, torna-se afetividade. A afetividade perdeu, por sua vez, a evidência das alterações orgânicas (proprioceptivas ou interoceptivas ${ }^{8}$ ), mas integrou-se ao desenvolvimento e construção do eu e do mundo externo, dando um "colorido" a essas manifestações.

A consciência de si surge, inicialmente, por meio da emoção. Ao final do primeiro ano de vida, ao se estabilizarem as respostas emocionais e se estabelecer um quadro mais ou menos fixo de reações emotivas, com o auxílio da maturação fisiológica e da interpretação desses sinais por parte do ambiente humano, a criança passa a tomar consciência de si como sujeito das reações. É ainda uma consciência muito primária e sincrética, ou seja, indiferenciada de forma precisa dos elementos e objetos que ela mesma carrega. Pelo desenvolvimento da simpatia, Wallon vai mostrando que, em seus primórdios, a criança confunde-se com a situação na qual está agindo. É a criança que chora, pois acabam de arrancar um dos braços de uma boneca representada em um desenho. Ou a outra que olha assustada para as próprias mãos, que minutos antes seguravam um copo, ao escutar o barulho de um copo quebrar-se na sala contígua a sua. O erro de grande parte da psicologia, vai dizer Wallon, é supor que a individualidade é um dado primário ou original, quando até mesmo a própria imagem corporal deve ser construída em um longo processo.

Provocar no meio social uma resposta em direção a si, confundir-se cognitivamente com esse meio, eis a tarefa primeira da emoção. É por meio da função postural ou tônica que ela ganha vida. A função postural é a responsável pela manutenção de um estado motor, pela garantia de uma tensão física mínima que possibilite a expressão corporal. Ela trabalha em conjunto com a função cinética ou clônica, responsável pela efetivação e regulação dos movimentos. No início do desenvolvimento, as configurações posturais, garantidas pela dialética entre as funções tônica e cinética, passam a prenunciar, pela intervenção do entorno social que dá significado a essas configurações posturais, a função simbólica ou representativa, que só ocorrerá, de fato, mais tarde (a partir de 2-3 anos até a adolescência). É o nascimento do gesto. Anteriormente, tratava-se apenas de ações desconexas e sem sentido para o próprio sujeito e agora, à medida que começam a se destacar intenções mais ou menos conscientes, é o gesto expressivo que predomina.

8 Proprioceptivo - percepção possibilitada pela ação dos músculos estriados esqueléticos. Ao mover meu braço, ainda que não o veja, posso "perceber" essa mudança corporal. Interoceptivo - percepção possibilitada pela ação da musculatura das vísceras. A criança que sente seu estômago mexer, mesmo não sabendo diferenciar essa sensação de outras similares ou próximas. Há, ainda, os mecanismos exteroceptivos, referentes aos cinco sentidos, reações decorrentes dos sistemas sensórios (tato, olfato, visão, gustação e audição). 
É preciso que haja a maturação dos centros nervosos correspondentes (mielinização das áreas frontais, occipitais, que se estenderá, igualmente, até a adolescência) para que surja, de fato, a função simbólica, quando, então, a criança saberá distinguir entre os objetos representados e seus respectivos modelos no espaço real - a consciência de que o objeto representado não é o objeto físico, mas apenas sua representação.

Mas ao mesmo tempo, no seu ápice, a emoção absorve toda a energia psíquica e impede a representação porque impede o desdobramento do sujeito com o objeto/real. Será preciso, portanto, uma função inibidora, que só advém com a maturação de outros centros nervosos que passam a controlar o movimento, para manter a emoção em um patamar estável e poder dar continuidade e desenvolvimento da representação - desde o gesto concreto carregado de significado até o pensamento mais abstrato.

Entre a ação e a espécie de consciência aí vinculada não há necessidade de um terceiro princípio. A consciência em seu início se confunde com a ação, como seu efeito e como seu estimulante ao mesmo tempo, e é deste modo que ela é igualmente seu objeto ou a sua meta mais próxima. Especificamente vinculada à função postural, a consciência segue-lhe todas as variações, mas, inversamente, torna-se seu motivo e pode suscitálas ou orientá-las. Toda e qualquer diferenciação de uma acarreta uma diferenciação da outra (WALLON, 1986, p. 146).

O parágrafo acima expressa bem a compreensão dialética que advoga Wallon. A emoção, por meio da função postural que carrega e impele ao gesto, prepara e possibilita a razão, e esta última, à medida que se estabelece, coloca a emoção em suspenso. Por essa razão, a psicóloga brasileira Heloísa Dantas (1990) assim se expressou sobre a dialética entre razão e emoção: "A emoção nasce da razão e vive de sua morte".

\section{Do gesto ao simbólico: contextualização do problema}

Passemos agora a uma breve digressão, no intuito de compreender qual o lugar das reflexões sobre o nascimento do pensamento simbólico na obra de Wallon. 
Wallon não se dedicou exclusivamente à compreensão desse tema. Sua preocupação central e seu trabalho, apesar da grande variedade de temas que abarcou e, igualmente, dos diversos envolvimentos práticos, encontra um ponto de confluência na produção de uma psicologia geral. Isso fica em parte evidente quando entendemos ao que corresponde cada um de seus 3 livros originais: ${ }^{9}$

a) As origens do caráter (1934) foca especialmente a idade de 0 a 2 anos - os principais temas abordados são o desenvolvimento do caráter e o papel da emoção neste. Caráter, para Wallon, é a forma mais estável de responder aos estímulos do ambiente. Ele tem relações imediatas com a emoção e com o corpo. Já o eu é a produção de uma identidade, singularidade, que culmina ao final do período da adolescência. Relação com a cognição e com o outro (social).

b) Do ato ao pensamento (1942) tem como objeto central de sua investigação a criança dos 2 aos 6 anos - A principal questão que quer responder Wallon neste livro é: "De onde vem o pensamento?" Trata-se das relações do gesto, do ato, da imitação com o pensamento simbólico.

c) As origens do pensamento na criança (1945), no qual Wallon dedica-se à criança de 5 a 12 anos - Aqui, Wallon quer explicar como se desenvolve o pensamento verbal. O pensamento é entendido como um conjunto. Inicialmente, resume-se ao "par" para, mais tarde, tornar-se o conceito. É o relacionamento dialético entre os dois elementos do par, o comunicar algo para alguém.

No seu conjunto, esses três livros abarcam a explicação do desenvolvimento humano de 0 aos 12,13 anos, do recém-nascido à adolescência. Entendemos esse conjunto de obras como resposta a um projeto de psicologia. Wallon almeja a construção da psicologia da pessoa completa, e o resultado produzido nesses três livros pode ser considerado sua realização.

Assim, embora seja desnecessário dizer que essa é uma interpretação que

${ }^{9} \mathrm{O}$ adjetivo "original" refere-se, unicamente, ao fato de que, nas três obras citadas, Wallon irá preocupar-se mais em construir sua teoria do que, como ocorre em "A vida mental" (1938) e "A evolução psicológica da criança" (1941), efetuar, em grande medida, mas não exclusivamente, uma síntese de toda sua produção. 
corre o risco de reduzir o escopo de interesses da obra walloniana, podemos afirmar que, no que concerne ao livro Do ato ao pensamento, em que haverá uma maior explicitação de sua teoria sobre o nascimento do pensamento simbólico ou representacional, este ocupa o lugar, no conjunto da obra, justamente da explicação da passagem entre uma psicologia marcada especialmente pelos comportamentos emocionais e pela inteligência das situações ( 0 a 3 anos), para outra, na qual a cognição vem suplantando a emoção e na qual se encontra presente o pensamento representativo ou simbólico. Cabe, pois, nessa obra, apresentar como se dá a transição entre esses dois "mundos".

\section{Do gesto ao simbólico: Wallon sobre a formação do símbolo}

O bebê humano, ao nascer, dispõe apenas de alguns recursos para conseguir sobreviver; o sistema nervoso autônomo (SNA) já está suficientemente desenvolvido para regular a respiração, os ciclos de sono e vigília e o bombeamento sanguíneo pelo coração. Não obstante, o controle da temperatura e o sistema postural, garantidos pela função tônica, ainda não se encontram totalmente desenvolvidos. De fato, nossa espécie é caracterizada por um longo período de maturação biológica e, especialmente, neurológica, após o nascimento. A isso chamamos de exterogestação (Gould, 1999; MonTAGNu, 1988). A criança nesse período, portanto, age de maneira impulsiva, com movimentos limitados ainda pela falta de maturação neurológica, mas que expressam já suas primeiras emoções. Podemos pensar que ela estará, de fato, aprendendo a lidar com os inúmeros estímulos que lhe advêm dos mecanismos extero, próprio e interoceptivos. Os primeiros atos serão, portanto, movimentos impulsivos, em grande parte desordenados, mas carregados de significado emocional. O bebê humano, por essa razão, age primeiramente em direção ao meio humano, para só mais tarde mobilizar-se perante o mundo físico.

À medida que os comportamentos vão se aperfeiçoando e o conjunto de reações emocionais - choro, raiva, sono, regojizo, etc. - passa a se delimitar com mais clareza e a mostrar certa estabilidade, a criança vai, ao mesmo tempo, controlando seus movimentos, tornando-os intencionais, expressivos, e construindo a consciência de si. Para Wallon, o desenvolvimento motor e o mental estão intimamente correlacionados desde sua origem. Assim, a consciência não é um dado original, ela não está presente desde o primeiro momento, mas é o resultado da síntese dialética derivada da maturação, do social e da experiência pessoal dessas suas reações, o que permite ao bebê utilizá-las de forma mais instrumental (WaLlon, 1934, 1938, 1942). 
Desse modo, não é qualquer ato que se tornará símbolo ou que culminará no símbolo, mas exclusivamente o gesto, ou ato carregado de intenção e, por isso mesmo, expressivo. $\mathrm{O}$ gesto prefigura o símbolo, assim como o grito prenuncia a palavra. Entre um e outro, contudo, existe filiação e oposição. A criança terá de desenvolver sua capacidade de controlar os gestos e movimentos para que a representação simbólica apareça. Mas, para que a transição entre o motor e o representacional ocorra, é preciso ainda que surja uma nova função psicológica: a função simbólica.

A representação "[...] apenas se utiliza da função simbólica da linguagem, ela é, ela mesma, certo nível da linguagem e da função simbólica" (WAllon, 1942/1970, p. 190). Wallon (1942/1970, p. 192) afirma que a função simbólica - "o poder de buscar para um objeto sua representação e para sua representação, um signo" - pode existir sem que existam as palavras: na afasia, por exemplo. E, ao contrário, quando existem palavras, como no caso do papagaio ou no macaco adestrado, não significa que exista função simbólica. Desse modo,

Longe de ser elemento inicial e final, as palavras dela são, ao contrário, apenas o efeito. Elas aí possuem uma existência de qualquer sorte contingente, o essencial sendo a função que permite substituir ao conteúdo real, intenções ou pensamentos e imagens que lhe exprimam sons, gestos ou mesmo objetos, que só possuem com eles relações com o ato pelo qual a ligação se opera. É a este poder de substituição que a função simbólica reconduz. Ela não é a simples soma de gestos determinados. Ela é aquilo que estabelece uma ligação entre um gesto qualquer a título de significante e um objeto, um ato ou uma situação, a título de significado. Ela não é, além disso, adição, mas desdobramento (WALLON, 1942/1970, p. 192).

É a função simbólica, portanto, que possibilita a passagem entre um pensamento concreto e outro abstrato ou representativo. Ela é uma decorrência do desenvolvimento orgânico e, nos casos em que estiver ausente, o sujeito não saberá relacionar um objeto com seu respectivo signo ou representante. No entanto, seu surgimento, por volta dos dois anos de idade, não garante ainda que o pensamento representativo esteja em pleno funcionamento. É necessário um último e principal passo: a representação, garantida pela função simbólica, toma corpo por meio da linguagem, e terá de aprender a configurar-se no es- 
paço-tempo mental. Com a inteligência concreta, a noção de espaço já havia sido conquistada, mas agora a linguagem introduz uma nova noção espacial. As palavras devem ocupar uma seqüência, um ritmo, para se adequarem ao intercâmbio social. Embora as duas inteligências sejam de naturezas distintas, opondo-se espaço concreto e espaço mental, têm, ambas, um terreno comum: a intuição espacial. É nesse terreno, portanto, que são solidárias.

O longo caminho que a criança deve percorrer para essa construção fica evidente pelo seu percurso no uso das palavras e das frases. Inicialmente, o bebê parece compreender várias frases e palavras, antes mesmo de poder enunciá-las, o que mostra uma impregnação da linguagem e uma relação com seus aspectos global e afetivo, deixando em segundo plano seus elementos constitutivos: a palavra, imagem, etc. Num segundo momento, a criança enuncia as primeiras palavras-frase. E, finalmente, aprende a distribuir no tempo o que sentiu e pensou. Por muito tempo, a criança só saberá falar por frases justapostas, sem conexão entre si.

Entre a palavra e o ato há, portanto, solidariedade e oposição. Solidariedade, pois ambos deverão resolver o problema da colocação no espaço-tempo. Oposição porque um é dado pelo concreto e é gerido pelo sujeito, o outro deve submeter-se ao crivo do social, que é ao mesmo tempo cultural e histórico. Os dois estão presentes no decorrer do desenvolvimento, mas, no momento da transição, é preciso que os conflitos sejam resolvidos. É o nascimento do pensamento representativo.

Para Wallon, desse modo, a passagem entre a inteligência sensório-motora e o pensamento simbólico se dá pela transformação e complexificação do ato motor, que se vê opondo-se a uma outra função: a representação. A representação é garantida pela função simbólica, mas só é desenvolvida no contexto social, uma vez que nasceu, no decorrer da filogenia da espécie, justamente como forma de contato entre os membros de uma comunidade. "As mesmas causas que fizeram do homem o animal social que ele é, deram-lhe também a aptidão para formar representações" (WALLON, 1942/1970, p. 190).

O percurso do ato ao pensamento é marcado por contradições e antagonismos. Inicialmente, o ato é sincrético, indiferenciado com a situação na qual opera. Aos poucos, no entanto, vai ganhando proficiência no uso do espaço circundante, a ponto de poder resolver os novos problemas que possam the advir. No entanto, o bebê humano nasce em um ambiente lingüístico, onde a linguagem é objeto de trocas expressivas, comunicação e representação. Ela será entendida como um objeto, do qual também terá de compreender a utilidade. 
Ato motor, proficiência no uso do espaço concreto, gesto, simulacro, imitação, proficiência no uso dos signos e sua correta utilização no espaço mental, representação mental ou pensamento: eis os elementos que se seguem e se intercalam, segundo a proposta de Wallon, não propriamente em uma seqüência linear, para a passagem entre um mundo e outro. Entre um e outro há oposição e nascimento. Mas essa seqüência não é fortuita, é gerida pela organização biológica e psicológica. Responde a uma maturação orgânica e busca, em cada momento, a formação da pessoa.

Em uma sociedade como a nossa, baseada no comportamento simbólico, entender como se dá, qual a origem e desenvolvimento do pensamento simbólico pode ser conhecimento de grande valia.

\section{REFERÊNCIAS}

CASSIRER, E. Antropología filosófica: introducción a una filosofía de la cultura. México: Fondo de Cultura Económica, 1945.

DANTAS, H. A infância da razão: uma introdução à psicologia da inteligência de Henri Wallon. São Paulo: Manole, 1990.

DELOACHE, J. Mindful of symbols. Scientific American, August, 2005.

DELOACHE, J. S. Shrinking trolls and expanding minds: early symbolic development. Psychological Science Agenda, p. 8-9, May/June 1996.

GALVÃO, I. Wallon: uma concepção dialética do desenvolvimento. Petrópolis: Vozes, 1996.

JALLEY, E. Preface. In: WALLON, H. L'evolution psychologique de l'enfant. Paris: Armand Colin, 2002.

. Une dialectique entre la nature et la histoire... In: WALLON, H. Psychologie et dialectique: écrits de 1926 a 1961. Paris: Messidor/Éditions Sociales, 1990.

.Wallon et Piaget: pour une critique de la psychologie contemporraine. Paris: L'Harmattan, 2006.

MONTAGNU, A. Tocar: o significado humano da pele. São Paulo: Summus, 1988. 
NICOLAS, S. Henri Wallon (1879-1962) au Collège de France. Bulletin de Psychologie, tomo 56, n. 1, 2003.

TRAN-THONG. Estádios e conceitos de estádio de desenvolvimento da criança na psicologia contemporânea. Lisboa: Aprofundamento, 1987. $2 \mathrm{v}$.

TREVARTHEN, C. An apreciation of the interpersonal psychology of Henri Wallon. Enfance, tomo 47, n. 1, 1993.

WALLON, H. As origens do caráter. São Paulo: Nova Alexandria, 1934/1995.

. Função proprioplástica. In: WEREBE, M. J. G.; NADEL-BRULFERT, J. (Orgs.). Henri Wallon. São Paulo: Ática, 1938/1986.

. De l'acte à la pensée. Paris: Flamarion, 1942/1970.

ZAZZO, R. Conduites et conscience. Neuchâtel: Delachaux et Niestlé, 1962.

. Henri Wallon - psicologia e marxismo. Lisboa: Vega, 1978.

. Janvier 1945: découverte de l'imitation néo-natale? Rev. Psychologie Française, v. 33, n. $1 / 2,1988$.

. Para onde vai a psicologia da criança? Campinas: Papirus, 1989.

. Henri Wallon: souvenirs. Enfance, n. 1, 1993.

Texto recebido em 14 dez. 2006

Texto aprovado em 23 abr. 2007 
